\title{
RATIONALE OF INCORPORATING SERUM ANTI-MULLERIAN HORMONE ESTIMATIONS IN DIAGNOSING PREMATURE OVARIAN FAILURE
}

\author{
Pranay Phukan', Surajeet Boruah ${ }^{2}$
}

${ }^{1}$ Associate Professor, Department of Obstetrics and Gynaecology, Assam Medical College and Hospital, Dibrugarh, Assam. 2Postgraduate Trainee, Department of Obstetrics and Gynaecology, Assam Medical College and Hospital, Dibrugarh, Assam.

ABSTRACT

\section{BACKGROUND}

The study was conducted with an idea to evaluate the occurrence of premature ovarian failure, to find out the different aetiologies, clinical manifestations and to assess the fertility status in patients of POF attending Gynaecology Outpatient Department of Assam Medical College and Hospital, Dibrugarh. The role of estimation of serum AMH in these women was considered as an integral part of the study.

\section{MATERIALS AND METHODS}

A detailed clinical history and examination was conducted on all the subjects and estimation of serum levels of LH, FSH and AMH were performed using the Immunotech EIA AMH/MIS assay (Beckman-Coulter Inc., Marseille, France). Karyotyping was considered where specially indicated.

\section{RESULTS}

In the present study, the mean age of presentation was $30.4 \pm 6.17$ years. Maximum number of patients (30\%) were in the age group of 36-40 years. The mean age at presentation is 30.4 \pm 6.17 years with range from $20-39$ years. In the present study, $43.33 \%$ of the patients had very low levels of AMH. Maximum number of patients with low AMH levels were in 36-40 years of age group (31.67\%). In our study, we also found concordance and discordance between FSH and AMH levels in some of the patients.

\section{CONCLUSION}

Because AMH levels are strongly correlated with the size of the follicle pool and because of the lack of cycle variations, serum levels of AMH are a good candidate for inclusion in standard diagnostic procedure to assess POF. The prospective assessment of FSH and AMH in consideration with female age and thus can help in predicting oocyte yields in women with infertility.

\section{KEYWORDS}

Ovarian Failure, Anti-Mullerian Hormone, Infertility.

HOW TO CITE THIS ARTICLE: Phukan P, Boruah S. Rationale of incorporating serum anti-Mullerian hormone estimations in diagnosing premature ovarian failure. J. Evolution Med. Dent. Sci. 2016;5(86):6379-6383, DOI: 10.14260/jemds/2016/1443

\section{BACKGROUND}

The term primary ovarian insufficiency has been suggested ${ }^{1,2}$ noting that this term was first used by the prominent endocrinologist Fuller Albright as early as 1942.3 The definition of POF in the present study is that the women aged younger than 40 years with amenorrhea or irregular menstruation or infertility with elevated FSH levels.

Idiopathic POF represents the most extreme phenotype of diminished ovarian reserve at young age. According to the Stages of Reproductive Ageing Workshop (STRAW) classification, there is a subgroup known as "Incipient Ovarian Failure" (IOF) or late reproductive ageing (Stage 3) characterised by elevated FSH levels and regular menstrual cycle. 4

Nowadays, more direct ovarian markers are available to measure ovarian function or reserve inhibin B, AFC (Antral Follicle Count) and anti-Mullerian hormone (AMH). AMH has been examined in numerous studies and is an established

Financial or Other, Competing Interest: None.

Submission 04-08-2016, Peer Review 26-09-2016,

Acceptance 03-10-2016, Published 26-10-2016.

Corresponding Author:

Dr. Pranay Phukan,

Seujpur, Dibrugarh, Assam.

E-mail: pranayp4@yahoo.com

DOI: $10.14260 /$ jemds $/ 2016 / 1443$ ovarian marker for poor response to in vitro fertilisation, polycystic ovary syndrome, hypogonadotropic hypogonadism and also age at menopause. ${ }^{5-7}$ The ovarian marker, especially AMH gives more accurate information of ovarian follicle quantity in young hypergonadotropic patients than FSH.5-8 $\mathrm{AMH}$, may be useful to determine the follicular reserve when POF is suspected. AMH levels do not vary with cycle day. ${ }^{9}$

Young women who experience loss of menstrual irregularity for three or more consecutive months should be evaluated at their first visit. ${ }^{10}$ Decline of reproductive potential correlates with the process of follicular depletion and diminished oocyte quality, factors referred to as ovarian reserve. ${ }^{11}$ The most important aspect of diminished ovarian reserve is the associated decline in reproductive potential fertility, it cannot be restored if the diagnosis is made after complete follicular depletion. ${ }^{12}$

\section{METHODS}

The women of age less than 40 years, coming to Gynaecological OPD, Assam Medical College and Hospital with menstrual irregularities for at least 3-4 months were selected for the study. Patients with menstrual irregularities due to pregnancy/lactation, diagnosed cases of acquired intrauterine pathology causing menstrual irregularity and PCOS were excluded from the study.

Detailed history of the patient was taken including age, 
age at menarche, duration of menstrual irregularity, past pregnancies, associated disorders, symptoms like hot flushes, any genitourinary complaints, any type of infection, autoimmune disorders, any pelvic surgery, endometriosis and probable aetiology and pathophysiology of POF, risk factors including lifestyle, socioeconomic status and emotional factors were assessed. In indicated cases, karyotyping was done. Ultrasonography of the pelvic organs was done. An examination involving height and weight measurements for BMI and a general systemic and pelvic examination was done.

Laboratory investigations like serum FSH, LH, AMH were performed using the Immunotech EIA AMH/MIS assay (Beckman-Coulter Inc., Marseille, France). Serum FSH was estimated on D3 of menstrual cycle and estimation was done on at least two occasions 4-6 weeks apart. Similarly, LH levels were also estimated on D3 of cycles. Samples for AMH estimation was collected in the morning hours irrespective of the menstrual cycle. AMH levels less than $2.19 \mathrm{ng} / \mathrm{mL}$ were considered as low levels. Patients with serum FSH more than $30 \mathrm{IU} / \mathrm{L}$ with menstrual irregularities were assigned as POF.

\section{RESULTS}

In the present study mean age of the patients was 30.4 years and median was 30 years with range from 20 to 39 years. In a study by Van Der Merwe et al (1981),13 the mean age was 29.5 years. In Alper et al (1985),14 it was found to be 30.2 years.

In the present study, the mean age of menarche was 12.85 years and maximum number of patients were having menarche at 13 years of age. Alper et al (1985) ${ }^{14}$ and Goswami et al (2011) ${ }^{15}$ studied on patients with mean age of menarche at 12.85 and 14.2 years, respectively.

In the present study out of 25 patients of ovarian failure, $4 \%$ of patients are associated with primary amenorrhoea and $20 \%$ with secondary amenorrhoea. In a study by Kinch RAH et al (1965) ${ }^{16}$ and Maschak CA et al (1981), ${ }^{17} 10-28 \%$ of the patients with primary amenorrhoea had POF. Alper et al14 and Aiman and Smentex ${ }^{18}$ et al observed primary amenorrhoea in $3 \%$ and $8.57 \%$ of the patients respectively. Moraes et al (1967) ${ }^{19}$ and Alper et al (1985) ${ }^{14}$ studied 10\% of the patients of secondary amenorrhoea associated with POF.

Day 3 serum FSH concentration is a simple measurement routinely used to assess ovarian reserve and ovarian responsiveness to stimulation.20,21 In the present study, $56.66 \%$ of patients had serum FSH level less than $10 \mathrm{IU} / \mathrm{L}$ and $16.66 \%$ of the patients had serum FSH level more than 31 $\mathrm{IU} / \mathrm{L}$ and the rest of the patients $(26.67 \%)$ had FSH levels between (11-30) IU/L.

Studies done by Knauff et al (2008) ${ }^{22}$ divided patients into Transitional Ovarian Failure (TOF) and POF according to which in the present study $60 \%$ of the patients were in TOF group and $40 \%$ were in POF group. This suggests that in the present study a larger group of population was in transitional phase of ovarian failure. Similar studies which observed that number of female patients presenting with elevated FSH levels is suggestive of reduced ovarian reserve with or without cycle abnormality is increasing. 23

In the present study, patients with age more than 35 years with elevated FSH levels were $40 \%$ and in patients with age less than 35 years, value was 32\%, 26-30 years and 21-25 years of age $12 \%$ each and $4 \%$ of the cases were in age group upto $20 \%$. This shows a positive relation of increasing age with increasing FSH levels. ${ }^{24}$

AMH may provide a more accurate assessment of the follicle pool in young hypergonadotropic patients, especially in the clinically challenging subgroups of patients with elevated FSH levels and regular menses (Incipient Ovarian Failure) and in hypergonadotropic women with cycle disturbances not fulfilling the POF diagnostic criteria (Transitional Ovarian Failure). ${ }^{24}$

S. Tsepelidis et al (2007) ${ }^{25}$ studied that no significant fluctuation of the AMH level during the menstrual cycle was observed. Therefore, this hormone is particularly interesting for clinical evaluation of the ovarian reserve, as it may be used during the cycle any time.

Only few identified causes of POF are known.26,27,28 Svetlana et $\mathrm{al}^{29}$ and Bachelot et $\mathrm{al}^{30}$ observed $74.90 \%$ and $88.2 \%$ respectively for unidentified causes. In this study, $12 \%$ of the patients were associated with hypothyroidism. In $8 \%$ of patients of this study, the cause of ovarian failure was surgery like cystectomy and laparoscopy. Mumps oophoritis has also been considered to be a cause of POF. True incidence of post-oophoritis ovarian failure is unknown. In majority of cases, return of ovarian function occurs following recovery. Ovarian destruction occurs in $3 \%$ of women with pelvic tuberculosis. In the present study, one patient was found to be infected by tuberculosis.

In the present study, one patient of primary amenorrhoea was associated with Turner's syndrome. McDonough (1977) ${ }^{31}$ studied 82 patients with ovarian failure and found sex anomalies in 52 patients. The most frequent single cell anomaly was 45X0 (Turner's syndrome).

In the present study $56 \%$ of the patients of POF showed few follicles on ultrasound, $32 \%$ of the patients of POF showed multiple follicles and $12 \%$ of the patients had absent/streak/atrophied ovaries. Goswami et al (2011) ${ }^{15}$ reported $60 \%$ of the patients had few follicles, $30 \%$ of the patients had multiple follicles and in $10 \%$ of the patients follicles were not visualised.

\begin{tabular}{|c|c|c|}
\hline Types & $\begin{array}{c}\text { Number } \\
\text { (n=60) }\end{array}$ & $\begin{array}{c}\text { Percentage } \\
\text { (\%) }\end{array}$ \\
\hline Primary Amenorrhoea & 2 & 3.33 \\
\hline Secondary Amenorrhoea & 13 & 21.67 \\
\hline Hypomenorrhoea & 11 & 18.33 \\
\hline Oligomenorrhoea & 24 & 40.00 \\
\hline Polymenorrhoea & 4 & 6.67 \\
\hline Metrorrhagia/Menorrhagia & 6 & 10.00 \\
\hline \multicolumn{2}{|c|}{ Table 1: Distribution of Cases According } \\
to Menstrual Irregularities \\
\hline
\end{tabular}




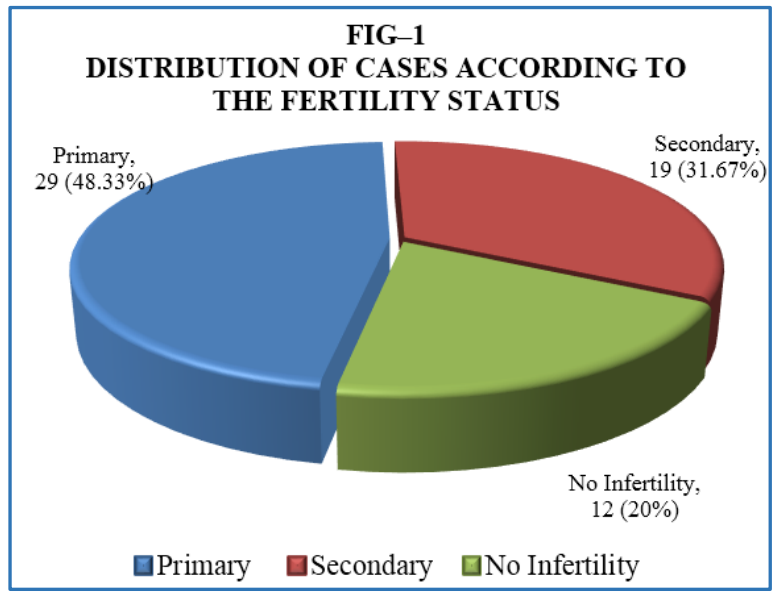

Young women who experience ovarian failure have to face the prospect of infertility (Conway 2000). ${ }^{32}$ Aiman and Smentek (1985) ${ }^{14}$ studied 35 patients of POF with infertility, Alzubaidi et al (2002) ${ }^{33}$ studied on 48 patients of POF, out of them $4 \%$ presented with infertility. In the present study, out of 25 cases of ovarian failure 19 cases had infertility.

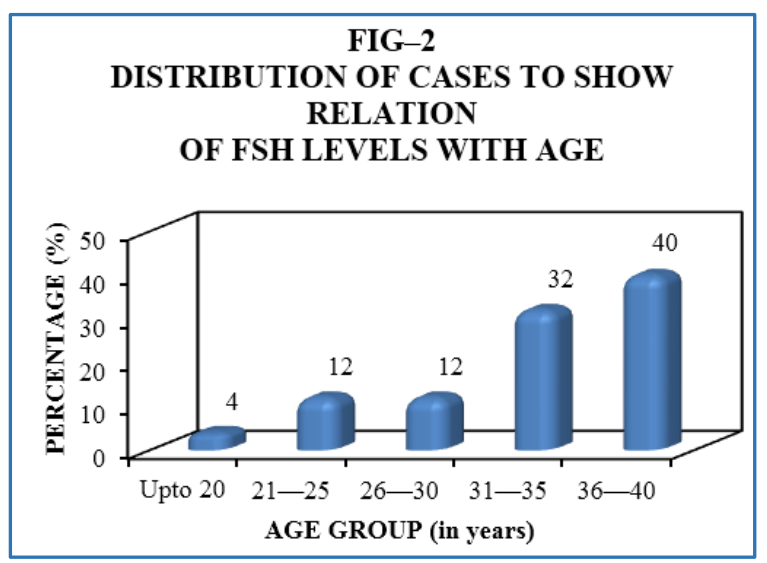

$\mathrm{AMH}$ is a promising test for diminished ovarian reserve. AMH value between $0.5-1.0 \mathrm{ng} / \mathrm{mL}$ was considered to be low. The lowest significant value of AMH recorded in our study was $0.04 \mathrm{ng} / \mathrm{mL}$. Seventeen patients had normal AMH levels (1.5-4.0) ng/mL.

In the present study, $43.33 \%$ of the patients had very low levels of AMH. Maximum number of patients with low AMH levels were in 36-40 years of age group (31.67\%). Similar studies by Scott et al (1989) ${ }^{21}$ and Van Rooij et al (2005) ${ }^{34}$ observed that AMH levels show a decreasing trend with age. The present study shows that age has a negative relation with AMH as $40 \%$ of the patients were in 36-40 years of age group, $22.22 \%$ of the patients were in $31-35$ years of age group, $20 \%$ in $26-30$ years and $8.88 \%$ each in 21-25 years and upto 20 years of age group.

In the present study 35 patients out of 48 were concordant in serum FSH and AMH levels; in that they were either normal or abnormal. Norbert Gleicher et al (2010) ${ }^{35}$ did similar studies, which suggests that in principle normal AMH is more important than normal FSH levels. La Marca et al $(2005)^{36}$ observed that all patients with POF have low AMH levels. The present study shows that all patients with POF have low $\mathrm{AMH}$ values. AMH was correlated with the clinical degree of follicle pool depletion in young women presenting with elevated FSH levels.

\begin{tabular}{|c|c|c|c|}
\hline \multicolumn{2}{|c|}{ AMH Level (ng/mL) } & Number (n) & (\%) \\
\hline Optimal & $4.00-6.80$ & 5 & 8.33 \\
\hline Satisfactory & $2.20-3.99$ & 10 & 16.67 \\
\hline Low & $0.30-2.19$ & 19 & 31.67 \\
\hline Very Low & $0.00-0.29$ & 26 & 43.33 \\
\hline \multicolumn{2}{|c|}{ Total } & $\mathbf{6 0}$ & $\mathbf{1 0 0 . 0 0}$ \\
\hline \multicolumn{2}{|c|}{ Table 2: Distribution ofCases According to AMH Levels } \\
\hline
\end{tabular}

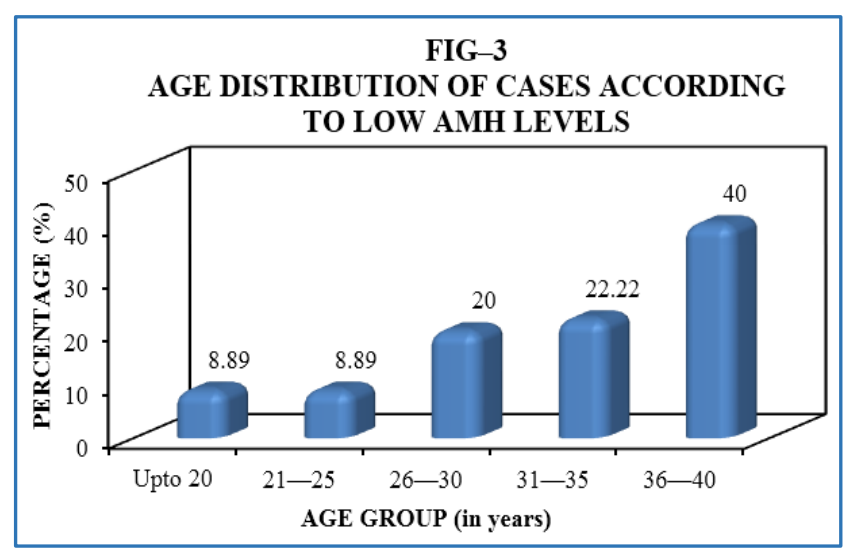

\begin{tabular}{|c|c|c|}
\hline Findings & Number (n) & Percentage (\%) \\
\hline Multiple Follicles & 8 & 32.00 \\
\hline Few Follicles & 14 & 56.00 \\
\hline $\begin{array}{c}\text { Absent Follicles/Streak/ } \\
\text { Atrophied Ovary }\end{array}$ & 3 & 12.00 \\
\hline Total & 25 & 100.00 \\
\hline \multicolumn{3}{|c|}{$\begin{array}{c}\text { Table 3: Distribution of the Cases } \\
\text { According to Ultrasonography }\end{array}$} \\
\hline
\end{tabular}

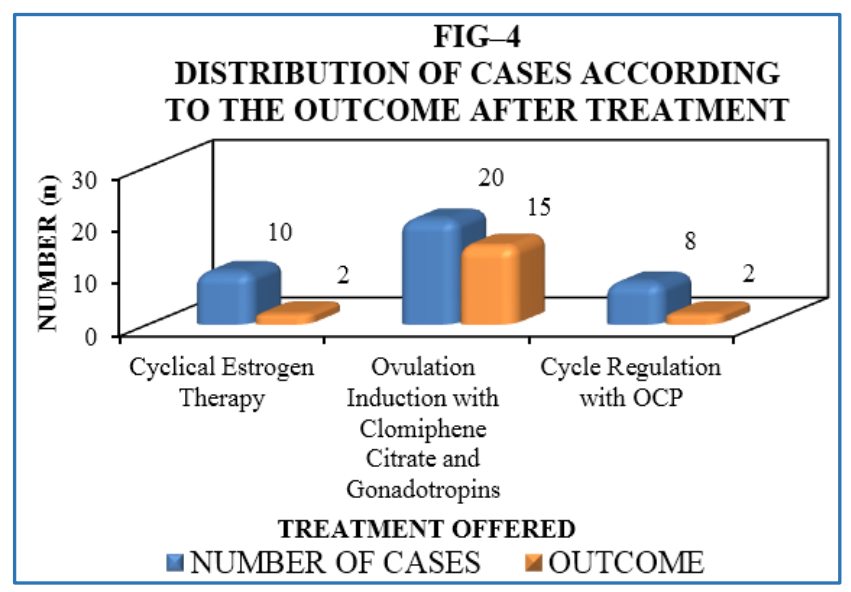

It has been observed that in some of the patients with normal serum FSH level is associated with normal serum AMH levels. In some of the patients with abnormal serum FSH levels, AMH level is less than normal. This is described as concordance of FSH and AMH levels.

In second observation of our study, we have found that some of the patients are having normal FSH levels associated with abnormal AMH levels. This is described as discordance of FSH and AMH levels. The following table showing Group I and Group IV are concordant and Group II and Group IV are discordant. 


\begin{tabular}{|c|c|c|c|c|}
\hline Group & $\begin{array}{l}\text { FSH Level } \\
\text { (IU/L) }\end{array}$ & $\begin{array}{c}\text { AMH } \\
(\mathrm{ng} / \mathrm{mL})\end{array}$ & $\begin{array}{c}\text { Number } \\
(n)\end{array}$ & (\%) \\
\hline Group-I & $<10$ & $>2.19$ & 12 & 25.53 \\
\hline Group-II & $>10$ & $>2.19$ & 3 & 6.38 \\
\hline Group-III & $<10$ & $<2.19$ & 10 & 21.28 \\
\hline Group-IV & $>10$ & $<2.19$ & 22 & 46.81 \\
\hline \multicolumn{3}{|c|}{ Total } & 47 & 100.00 \\
\hline \multicolumn{5}{|c|}{$\begin{array}{l}\text { Table 4: Distribution of Cases Based on Concordance } \\
\text { or Discordance between FSH and AMH Levels }\end{array}$} \\
\hline
\end{tabular}

In the present study $56 \%$ of the patients of POF showed few follicles on ultrasound, $32 \%$ of the patients of POF showed multiple follicles and $12 \%$ of the patients had absent/streak/atrophied ovaries.

In the present study, out of 60 patients 48 patients were found to have infertility and were subjected to various treatments.

\section{CONCLUSION}

To conclude it could be emphasised that women with POF is a condition with multiple aetiologies and needs more aggressive evaluation of oligomenorrhoea and amenorrhoea. Loss of menstrual regularity can be a sign of ovarian insufficiency. Young women who develop spontaneous POF are deeply upset by the diagnosis, partly due to unexpected menopausal symptoms and also due to infertility. Therefore, early detection would provide better opportunity for early intervention and subsequently increased chances of favourable outcomes. The accurate assessment of ovarian reserve will revolutionise the management of women requesting assisted conception, at least for those who are considering delaying family.

Currently, there are no reliable markers or clinical methods to assess ovarian reserve accurately in the normal menstruating premenopausal women.

Because AMH levels are strongly correlated with the size of the follicle pool and because of the lack of cycle variations, serum levels of AMH are a good candidate for inclusion in standard diagnostic procedure to assess POF. The prospective assessment of FSH and AMH in consideration with female age thus can help in predicting oocyte yields in women with infertility.

\section{REFERENCES}

1. Welt CK. Primary ovarian insufficiency: a more accurate term for premature ovarian failure. Clin Endocrinal (Oxf) 2008;68(4):499-509.

2. Nelson LM, Popat V. Ovarian insufficiency. eMedicine. Available from: http: //www. emedicine. com/med/TOPIC3374. htm. Retrieved June 9, 2008.

3. Albright F, Smith PH, Fraser R. A syndrome characterized by primary ovarian insufficiency and decreased stature: report of 11 cases with a digression on hormonal control of axillary and pubic hair. Am J Med Sciences 1942;204(5):625-48.

4. Farhi J, Homburg R, Ferber A, et al. Non response to ovarian stimulation in normogonadotrophic, normogonadal women: a clinical sign of impending onset of ovarian failure pre-empting the rise in basal follicle stimulating hormone levels. Hum Reprod 1997;12(2):241-243.
5. Broekmans FJ, Kwee J, Hendriks DJ, et al. A systematic review of tests predicting ovarian reserve and IVF outcome. Hum Reprod Update 2006;12(6):685-718.

6. Broekman FJ, Visser JA, Laven JS, et al. Anti-Mullerian hormone and ovarian dysfunction. Trends Endocrinol Metab 2008;19(9):340-7.

7. van Disseldorp J, Faddy MJ, Thmmen AP, et al. Relationship of serum antimu llerian hormone concentration to age at menopause. J Clin Endocrinol Metab 2008;93(6):2129-34.

8. Seifer DB, MacLaughlin DT, Christian BP, et al. Early follicular serum mullerian-inhibiting substance levels are assosciated with ovarian response during assisted reproductive technology cycles. Fertil Steril 2002;77(3):468-71.

9. Mishell DRJ, Stenchever MA, Droegemueller W, et al. Primary and secondary amenorrhoea. Comprehensive Gynecology. St Louis: Mosby 1997:1043.

10. Nelson LM. Spontaneous premature ovarian failure: young women, special needs. Menopause Management magazine 2001;10(4):2-6.

11. Richardson SJ, Senikas V, Nelson JF. Follicular depletionduring the menopausal transition: evidence for accelerated loss and ultimate exhaustion. J Clin Endocrinol Metab 1987;65(6):1231-7.

12. Beck-Peccoz P, Persani L. Premature ovarian failure. Orphanet Journal of Rare Diseases 2006;1:9.

13. Van Der Merwe JV. Premature Ovarian Failure. S Afr Med J 1981;59:104.

14. Alper MM, Garner PR. Premature ovarian failure: its relationship to autoimmune disease. Obstet Gynecol 1985;66(1): 27-30.

15. Goswami D, Arif A, Saxena A, et al. Idiopathic primary ovarian insufficiency: a study of serial hormonal profiles to assess ovarian follicular activity. Hum Reprod 2011;26(8):2218-25.

16. Kinch RAH, Plunkett ER, Smout MS, et al. Primary ovarian failure. A clinicopathological and cytogenetic study. Am J Obstet Gynecol 1965;91:630-44.

17. Mashchak CA, Kletzky OA, Davajan V, et al. Clinical and laboratory evaluation of patients with primary amenorrhea. Obstet Gynecol 1981;57(6):715-21.

18. Aiman J, Smentek C. Premature ovarian failure. Obstet Gynecol 1985;66(1):9-14.

19. Moraes-Ruehsen M, Jones GS. Premature ovarian failure. Fertil Steril 1967;18(4):440-61.

20. Goldenberg RL, Grodin JM, Rodbard D, et al. Gonadotropinin women with amenorrhea. The use of plasmafollicle-stimulating hormone to differentiate women withand without ovarian follicles. Am J Obstet Gynecol 1973;116(7):1003-12.

21. Scott RT, Toner JP, Muasher SJ, et al. Follicle-stimulating hormone levels on cycle day 3 are predictive of in vitro fertilization outcome. Fertil Steril 1989;51(4):651-4.

22. Knauff EA, Eijkemans MJ, Lambalk CB, et al. Antimullerian hormone, inhibin $\mathrm{B}$, and antral follicle count in young women with ovarian failure. J Clin Endocrinol Metab 2008;94(3).

23. Broekmans FJ, Knauff EA, te Velde ER, et al. Female reproductive ageing: current knowledge and future trends. Trends Endocrinol Metab 2007;18(2):58-65. 
24. McTavish KJ, Jimenez M, Walters KA, et al. Rising folliclestimulating hormone levels with age accelerate female reproductive failure. Endocrinology 2007;148(9): 4432-9.

25. Tsepelidis S, Devreker F, Demeestere I, et al. Stable serum levels of anti-müllerian hormone during the menstrual cycle: a prospective study in normo-ovulatory women. Hum Reprod 2007;22(7):1837-40.

26. Nelson LM. Clinical practice. Primary ovarian insufficiency. N Engl J Med 2009;360(6):606-14.

27. Panay N, Kalu E. Management of premature ovarian failure. Best Prac Res Clin Obstet Gynecol 2009;23(1):129-40.

28. Rebar RW. Premature ovarian failure. Obstet Gynecol 2009;113(6):1355-63.

29. Vujovic S, Ivovic M, Tancic-Gajic $M$, et al. Premature ovarian failure. Srp Arh Celok Lek 2012;140(11-12): 806-11.

30. Bachelot A, Rouxel A, Massin N, et al. Phenotyping and genetic studies of 357 consecutive patientspresenting with premature ovarian failure. Eur J Endocrinol 2009;161(1):179-87.
31. McDonough PG, Byrd JR, Tho PT, et al. Phenotypic and cytogenetic findings in eighty-two patients with ovarian failure-changing trends. Fertil Steril 1977;28(6):638-41.

32. Conway GS. Premature ovarian failure. British Medical Bulletin 2000;56(3):643-9.

33. Alzubaidi NH, Chapin HL, Vanderhoof VH, et al. Meeting the needs of young women with secondary amenorrhoea and spontaneous premature ovarian failure. Obstet Gynecol 2002;99(5 Pt 1):720-5.

34. van Rooij IA, Broekmans FJ, Scheffer GJ, et al. Serum antimullerianhormone levels best reflect the reproductive decline with age innormal women with proven fertility: a longitudinal study. Fertil Steril 2005;83(4):979-87.

35. Gleicher N, Weghofer A, Barad DH. Discordances between follicle stimulating hormone (FSH) and antimüllerian hormone (AMH) in female infertility. Reproductive Biology and Endocrinology 2010;8:64.

36. La Marca A, De Leo V, Giulini S, et al. Anti-mullerian hormone in premenopausal women and after spontaneous or surgically induced menopause. J Soc Gynecol Investig 2005;12(7):545-8. 